\title{
Moderate red wine consumption is associated with a lower prevalence of the metabolic syndrome in the PREDIMED population
}

Anna Tresserra-Rimbau ${ }^{1,2}$, Alexander Medina-Remón ${ }^{2,3}$, Rosa M. Lamuela-Raventós ${ }^{1,2}$, Monica Bulló ${ }^{2,4}$, Jordi Salas-Salvadó $^{2,4}$, Dolores Corella ${ }^{2,5}$, Montserrat Fitó ${ }^{2,6}$, Alfredo Gea ${ }^{7}$, Enrique Gómez-Gracia ${ }^{2,8}$, José Lapetra $^{2,9}$, Fernando Arós ${ }^{2,10}$, Miquel Fiol ${ }^{2,11}$, Emili Ros ${ }^{2,12}$, Luis Serra-Majem ${ }^{2,13}$, Xavier Pintó ${ }^{2,14}$, Miguel A. Muñoz ${ }^{15}$, Ramón Estruch ${ }^{2,3 *}$ and on behalf of the PREDIMED Study Investigators

${ }^{1}$ Nutrition and Food Science Department, XaRTA, INSA, Pharmacy School, University of Barcelona, Barcelona, Spain

${ }^{2}$ CIBER CBO6/O3 Fisiopatología de la Obesidad y la Nutrición (CIBERObn), Spain

${ }^{3}$ Department of Internal Medicine, Hospital Clinic, Institut d'Investigacions Biomédiques August Pi i Sunyer (IDIBAPS),

University of Barcelona, Barcelona, Spain

${ }^{4}$ Human Nutrition Unit, School of Medicine, IISPV, University Rovira i Virgili, Reus, Spain

${ }^{5}$ Department of Preventive Medicine and Public Health, Nutrition and Food Sciences, School of Medicine, University of

Valencia, Valencia, Spain

${ }^{6}$ Cardiovascular Risk and Nutrition Research Group, Hospital del Mar d'Investigacions Biomèdiques (IMIM), Barcelona, Spain

${ }^{7}$ Department of Preventive Medicine and Public Health, School of Medicine, University of Navarra, Pamplona, Spain

${ }^{8}$ Department of Epidemiology, School of Medicine, University of Malaga, Málaga, Spain

${ }^{9}$ Department of Family Medicine, Primary Care Division of Sevilla, San Pablo Health Center, Sevilla, Spain

${ }^{10}$ Department of Cardiology, Hospital Txangorritxu, Vitoria, Spain

${ }^{11}$ Institut Universitari d'Investigació en Ciències de la Salut (IUNICS), Palma de Mallorca, Spain

${ }^{12}$ Lipid Clinic, Endocrinology and Nutrition Service, IDIBAPS, Hospital Clinic, Barcelona, Spain

${ }^{13}$ Department of Clinical Sciences, University of Las Palmas de Gran Canaria, Palmas de Gran Canaria, Spain

${ }^{14}$ Lipid and Vascular Risk Unit, Department of Internal Medicine, Hospital Universitari de Bellvitge, University of Barcelona,

L'Hospitalet de Llobregat, FIPEC, Barcelona, Spain

${ }^{15}$ Primary Care Division Catalan Institute of Health, Barcelona, Spain

(Submitted 1 July 2014 - Final revision received 8 September 2014 - Accepted 11 September 2014)

\section{Abstract}

Previous studies on the association between alcohol intake and the development of the metabolic syndrome (MetS) have yielded inconsistent results. Besides, few studies have analysed the effects of red wine (RW) consumption on the prevalence of the MetS and its components. As moderate RW drinkers have a better lipid profile and lower incidence rates of diabetes, hypertension and abdominal obesity, all components of the MetS, it was hypothesised that moderate RW consumption could be associated with a lower prevalence of the MetS. In the present cross-sectional study of 5801 elderly participants at a high cardiovascular risk included in the PREDIMED (Prevención con Dieta Mediterránea) study, 3897 fulfilled the criteria of the MetS at baseline. RW intake was recorded using a validated 137-item FFQ. Multiple logistic regression analysis was carried out to estimate the association between RW intake and the prevalence of the MetS.

Abbreviations: BP, blood pressure; HDL-c, HDL-cholesterol; MedDiet, Mediterranean diet; MetS, metabolic syndrome; PREDIMED, Prevención con Dieta Mediterránea; RW, red wine; SUN, Seguimiento Universidad de Navarra.

*Corresponding author: Dr R. Estruch, fax +34 93 2279236, email restruch@clinic.ub.es

"Publication of these papers was supported by unrestricted educational grants from Federación Española de Sociedades de Nutrición, Alimentación y Dietética (FESNAD), International Nut and Dried Fruit Council (INC), International Union of Nutritional Sciences (IUNS), Fundación Iberoamericana de Nutrición (FINUT), Centro de Investigación Biomédica en Red de la Fisiopatología de la Obesidad y Nutrición (CIBERobn) and Centro Interuniversitario di Ricerca sulle Culture Alimentari Mediterranee (Ciiscam). The papers included in this supplement were invited by the Guest Editors and have undergone the standard journal formal review process. They may be cited. The Guest Editors declare that Salas-Salvadó is a nonpaid member of the World Forum for Nutrition Research and Dissemination of the International Nut and Dried Fruit Council. Angel Gil is President of the Fundación Iberomericana de Nutrición, which is a non-paid honorary position. Lluis Serra-Majem is the President of the Scientific Committee of the Mediterranean Diet Foundation and Scientific Director of the CIISCAM (Centro Interuniversitario di Ricerca sulle Culture Alimentari Mediterranee), Universita La Sapienza di Roma which are both non-paid, honorary positions. Goretti Guasch is the Executive Director and Member of the Executive Committee of the International Nut and Dried Fruit Council, which is a paid position. Mònica Bulló declares no conflict of interest. 
Compared with non-drinkers, moderate RW drinkers ( $\geq 1 \mathrm{drink} / \mathrm{d}$ ) were found to have a reduced risk of prevalent MetS (OR 0.56, 95\% CI $0.45,0.68 ; P<0.001)$, a lower risk of having an abnormal waist circumference (OR 0.59, $95 \%$ CI $0.46,0 \cdot 77 ; P<0 \cdot 001$ ), low HDL-cholesterol concentrations (OR 0.42, $95 \%$ CI 0.32, 0.53; P<0.001), high blood pressure (OR 0.28, $95 \%$ CI $0.17,0.45 ; P<0 \cdot 001)$ and high fasting plasma glucose concentrations (OR $0.67,95 \%$ CI $0.54,0.82 ; P<0.001)$ after adjusting for several confounders. This association was found to be stronger in female participants, in participants aged $<70$ years and in participants who were former or current smokers. No significant association was found between RW intake ( $\geq 1 \mathrm{drink} / \mathrm{d}$ ) and TAG concentrations. In conclusion, moderate RW consumption is associated with a lower prevalence of the MetS in an elderly Mediterranean population at a high cardiovascular risk.

Key words: Red wine: Alcohol: Metabolic syndrome

The metabolic syndrome (MetS), a cluster of metabolic abnormalities that includes abdominal obesity, hypertriacylglycerolaemia, low HDL-cholesterol (HDL-c) concentrations, hypertension and hyperglycaemia, has become a major public health concern ${ }^{(1)}$. It results from the interaction of multiple factors, including genetic and environmental factors, with the dietary habits playing a crucial role in its development ${ }^{(2)}$.

Previous studies have found both positive and negative effects of alcohol intake on the risk of $\mathrm{MetS}^{(3)}$. However, in a meta-analysis of observational studies, Alkerwi et al. ${ }^{(4)}$ showed that a favourable metabolic effect appeared to be restricted to moderate alcohol intake, namely $<20 \mathrm{~g} / \mathrm{d}$ in women and $<40 \mathrm{~g} / \mathrm{d}$ in men. While some authors have found no differences in the incidence rates of the MetS among consumers of various alcoholic drinks, others have reported lower incidence rates among wine drinkers ${ }^{(3,5)}$. However, using a longitudinal design in the SUN (Seguimiento Universidad de Navarra) study, BarrioLopez et al. ${ }^{(5)}$ found that consumers of at least seven alcoholic drinks per week had increased odds of developing the MetS, but they did not find any significant association between wine or liquor consumption and the MetS. Besides containing alcohol, red wine (RW) is rich in polyphenols, which may beneficially influence carbohydrate metabolism ${ }^{(6)}$ and blood pressure $(\mathrm{BP})^{(7,8)}$. Furthermore, different human intervention studies have shown that other foods rich in polyphenols increase HDL-c concentrations ${ }^{(9-11)}$; however, the few human studies that have been conducted on the effects of polyphenol-rich foods on abdominal adiposity have yielded conflicting results, with studies showing positive effects ${ }^{(12,13)}$ or no effect ${ }^{(14)}$

The purpose of the present study was to investigate the association between RW consumption and the prevalence of the MetS and its components in an elderly Mediterranean population at a high cardiovascular risk.

\section{Subjects and methods}

\section{Subjects}

A cross-sectional study was conducted using baseline data obtained from the cohort of the PREDIMED study. A detailed description of the study has been published previously ${ }^{(15)}$. This study was conducted according to the guidelines laid down in the Declaration of Helsinki, and all procedures involving human subjects/patients were approved by the Institutional Review Boards of the participating centres (Clinical Trial Registration: ISRCTN of London, England: 35739639). Written informed consent was obtained from all participants.
Of the 5969 participants from all the PREDIMED centres with complete biochemical analysis data, 140 who did not complete the FFQ at baseline and twenty-eight with extreme total energy intakes were excluded from the present study ${ }^{(16)}$. Thus, data from 5801 participants were available for the analyses.

\section{Assessment of population characteristics and dietary habits}

Dietary habits at baseline were evaluated using a validated 137 -item $\mathrm{FFQ}^{(17)}$. Daily food and nutrient intakes were estimated from the FFQ by multiplying the frequency of consumption by the average portion size. A validated 14-point questionnaire was also used ${ }^{(18)}$, but excluding alcohol intake, to assess the adherence to the traditional Mediterranean diet (MedDiet). The participants also filled out a general questionnaire on lifestyle habits, medication use and concurrent diseases and a validated Spanish version of the Minnesota Leisure Time Physical Activity Questionnaire ${ }^{(19)}$.

\section{Anthropometric measurements and blood analyses}

Body weight and height were measured with minimum clothing and no shoes, using calibrated scales and wall-mounted stadiometers, respectively. The BMI was calculated as weight in $\mathrm{kg}$ divided by the square of height in $\mathrm{m}$. Waist circumference was measured mid-way between the lowest rib and iliac crest using an anthropometric tape. The waist:height ratio was assessed by dividing the waist circumference by height, as a practical index for assessing central fat distribution. BP was measured in a sitting position, using a semi-automatic sphygmomanometer (Omron HEM-705CP), in triplicate with a 5 min interval between each measurement, and the mean of these values was recorded according to the procedures recommended by the European Hypertension Society ${ }^{(20)}$. Plasma glucose and lipid profiles were measured using an automatic analyser in a routine laboratory test. For patients with TAG concentrations $<400 \mathrm{mg} / \mathrm{dl}$, LDL-cholesterol concentrations were estimated using the Friedewald formula ${ }^{(21)}$.

\section{Categories of red wine intake}

The FFQ included questions concerning the intake of wines (RW, rosé wine, white wine and sparkling wine), beer, liquors and spirits. Standard drinks (hereafter referred to as 'drinks'), $10 \mathrm{~g}$ of pure alcohol, were used to categorise alcohol intake. The drinks included $100 \mathrm{ml}$ of wine, $250 \mathrm{ml}$ of beer, $65 \mathrm{ml}$ of 
liquors and $32 \mathrm{ml}$ of spirits. The participants were categorised into three groups based on their RW intake: non-drinkers; $0 \cdot 1-1 \mathrm{drink} / \mathrm{d} ;>1 \mathrm{drink} / \mathrm{d}$.

\section{Definition of the metabolic syndrome}

The MetS was defined in accordance with the updated harmonised International Diabetes Federation (IDF) and the American Heart Association/National Heart, Lung, and Blood Institute (AHA/NHLBI) criteria ${ }^{(22)}$. The participants were identified as having the MetS, as defined in the American Journal of Clinical Nutrition (AJCN/2014/086991 version 1), when they had at least three of the following components: (1) elevated waist circumference for European individuals $(>102 \mathrm{~cm}$ in men; $>88$ in women); (2) elevated TAG concentrations $(>150 \mathrm{mg} / \mathrm{dl}(1.7 \mathrm{mmol} / \mathrm{l}))$ or drug treatment for elevated TAG concentrations; (3) low HDL-c concentrations ( $\leq 40 \mathrm{mg} / \mathrm{dl}$ $(1.0 \mathrm{mmol} / \mathrm{l})$ in $\mathrm{men} ; \leq 50 \mathrm{mg} / \mathrm{dl}(1.3 \mathrm{mmol} / \mathrm{l})$ in women $)$ or drug treatment for low HDL-c concentrations; (4) elevated BP (systolic $\geq 130$ and/or diastolic $\geq 85 \mathrm{mmHg}$ ) or antihypertensive drug treatment; (5) elevated fasting glucose concentrations $(>100 \mathrm{mg} / \mathrm{dl}(5.5 \mathrm{mmol} / \mathrm{l}))$ or drug treatment for diabetes.

\section{Statistical analyses}

The means of continuous variables among the different RW intake groups were compared using one-way ANOVA with the Bonferroni post boc test. If the variable did not follow a normal distribution (skewness or kurtosis $>-2$ or $<2$ ), the corresponding non-parametrical Mann-Whitney and Kruskal-Wallis tests were performed. The $\chi^{2}$ test or the Fisher exact test was used for analysing categorical variables.

Pearson's correlation coefficients were calculated to test the linear association between the intake of RW and that of other alcoholic beverages (white and sparkling wines, beer, liquors and spirits), all as continuous variables.

The OR for the MetS and each of its components in the different RW intake categories were calculated using multiple logistic regression analysis, with the outcome as the dependent variable and the intake groups as independent variables. Multivariate models were adjusted for sex, age (continuous), BMI (continuous), smoking status (never, former and current), physical activity during leisure time (yes/no), energy intake (continuous), educational level and adherence to the Mediterranean food pattern excluding wine intake (continuous). Additional analyses stratified by sex, age groups ( $<70$ years and $\geq 70$ years) and smoking status (never/ever) were carried out and the effect modification of these variables with alcohol was evaluated using likelihood ratio tests for the product term introduced in the crude and fully adjusted models. All statistical analyses were conducted using IBM SPSS software version 19.0. All $t$ tests were twosided and $P$ values $<0.05$ were considered significant.

\section{Results}

A total of 5801 PREDIMED study participants (2433 men and 3368 women) at a high cardiovascular risk were included in the present study. The baseline characteristics of the study participants according to categories of energy-adjusted RW intake at baseline are summarised in Table 1. More than $50 \%$ of the study population did not consume RW (3037 participants), $36 \%$ consumed $<1 \mathrm{drink} / \mathrm{d}$ (2086 participants) and $12 \%$ consumed $>1 \mathrm{drink} / \mathrm{d}$ (678 participants). Of these, only 111 participants consumed $\geq 5$ drinks/d. Participants with the highest RW intake were found to more likely be men, current or former smokers, and more physically active and have a higher educational level. The dietary pattern of the participants distributed into RW intake categories is summarised in Table 2 . Those who drank more RW ( $>1$ drink/d) were found to have a higher intake of carbohydrates, protein, SFA, MUFA and PUFA, total cholesterol and total energy. Less frequent consumption of fruits, vegetables and dairy products was observed in the group of moderate/heavy drinkers, although no significant differences were observed in the adherence to the traditional MedDiet among the three groups.

The linear association between the intake of RW and that of other alcoholic beverages was also tested (Table 3). Although

Table 1. Baseline characteristics of participants from the PREDIMED (Prevención con Dieta Mediterránea) cohort according to categories of red wine (RW) intake at baseline (energy-adjusted)

(Number of participants; percentages; mean values and standard deviations)

\begin{tabular}{|c|c|c|c|c|c|c|c|}
\hline \multirow[b]{2}{*}{ Characteristics } & \multicolumn{2}{|r|}{ Non-drinkers } & \multicolumn{2}{|r|}{$0.1-1 \mathrm{drink} / \mathrm{d}$} & \multicolumn{2}{|r|}{$>1$ drink/d } & \multirow[b]{2}{*}{$P^{*}$} \\
\hline & $n$ & Percentage of the total & $n$ & Percentage of the total & $n$ & Percentage of the total & \\
\hline No. of participants (5801) & 3037 & 52.4 & 2086 & $36 \cdot 0$ & 678 & 11.7 & \\
\hline Sex, women & 2299 & $75 \cdot 7$ & 973 & $46 \cdot 6$ & 96 & $14 \cdot 2$ & $<0.001$ \\
\hline Current smoker & 276 & $9 \cdot 1$ & 324 & $15 \cdot 5$ & 193 & 28.5 & $<0.001$ \\
\hline Former smoker & 464 & $15 \cdot 3$ & 645 & 30.9 & 292 & 43.1 & $<0.001$ \\
\hline \multirow[t]{2}{*}{ Higher education } & 328 & $10 \cdot 8$ & 395 & $18 \cdot 9$ & 160 & $23 \cdot 6$ & $<0.001$ \\
\hline & Mean & SD & Mean & SD & Mean & SD & $P \dagger$ \\
\hline RW intake (units/d) & 0 & 0.0 & 0.51 & 0.4 & 2.9 & $1 \cdot 2$ & $<0.001$ \\
\hline Age (years) & $67 \cdot 9$ & $6 \cdot 0$ & $66 \cdot 3$ & $6 \cdot 2$ & $65 \cdot 7$ & $6 \cdot 1$ & $<0.001$ \\
\hline $\begin{array}{l}\text { Energy expenditure in } \\
\text { physical activity }(\mathrm{kJ} / \mathrm{d})\end{array}$ & $829 \cdot 3$ & $871 \cdot 1$ & $1042 \cdot 9$ & $1050 \cdot 0$ & $1398 \cdot 6$ & $1147 \cdot 0$ & $<0.001$ \\
\hline
\end{tabular}


Table 2. Dietary pattern of 5801 participants from the PREDIMED (Prevención con Dieta Mediterránea) cohort according to categories of red wine (RW) intake at baseline (energy-adjusted)

(Mean values and standard deviations)

\begin{tabular}{|c|c|c|c|c|c|c|c|}
\hline & \multicolumn{2}{|c|}{$\begin{array}{l}\text { Non-drinkers } \\
\quad(n \text { 3037) }\end{array}$} & \multicolumn{2}{|c|}{$\begin{array}{c}0.1-1 \text { drink/d } \\
(n \text { 2086) }\end{array}$} & \multicolumn{2}{|c|}{$\begin{array}{c}>1 \text { drink/d } \\
(n 678)\end{array}$} & \multirow[b]{2}{*}{$P^{*}$} \\
\hline & Mean & SD & Mean & SD & Mean & SD & \\
\hline \multicolumn{8}{|l|}{ Alcoholic beverages (units/d) } \\
\hline RW & 0.00 & 0.00 & 0.51 & 0.38 & 2.92 & 1.19 & $<0.001$ \\
\hline White, rosé and sparkling wines & $0 \cdot 10$ & 0.51 & 0.08 & 0.36 & 0.11 & 0.47 & 0.36 \\
\hline Beer & 0.09 & 0.37 & 0.22 & 0.56 & 0.37 & 0.79 & $<0.001$ \\
\hline Liquors/spirits & 0.005 & 0.06 & 0.01 & 0.08 & 0.03 & 0.10 & $<0.001$ \\
\hline \multicolumn{8}{|l|}{ Nutrient intake } \\
\hline Total energy intake & & & & & & & $<0.001$ \\
\hline $\mathrm{kJ} / \mathrm{d}$ & 8875.5 & 2174 & 9660 & $2185 \cdot 7$ & 10880 & $2118 \cdot 7$ & \\
\hline $\mathrm{kcal} / \mathrm{d}$ & $2121 \cdot 3$ & $519 \cdot 6$ & $2308 \cdot 8$ & 522.4 & $2600 \cdot 4$ & $506 \cdot 4$ & \\
\hline Carbohydrates $(\mathrm{g} / \mathrm{d})$ & $228 \cdot 3$ & $72 \cdot 4$ & $238 \cdot 7$ & $72 \cdot 7$ & $251 \cdot 3$ & $75 \cdot 2$ & $<0.001$ \\
\hline Protein $(\mathrm{g} / \mathrm{d})$ & $89 \cdot 2$ & 21.3 & $94 \cdot 3$ & 21.4 & $95 \cdot 7$ & $20 \cdot 3$ & $<0.001$ \\
\hline SFA $(g / d)$ & 23.7 & 8.5 & $26 \cdot 1$ & $8 \cdot 3$ & $26 \cdot 9$ & $8 \cdot 2$ & $<0.001$ \\
\hline MUFA $(g / d)$ & $46 \cdot 0$ & $15 \cdot 0$ & $50 \cdot 5$ & $14 \cdot 9$ & 52.9 & $14 \cdot 2$ & $<0.001$ \\
\hline PUFA $(g / d)$ & $14 \cdot 8$ & $6 \cdot 4$ & $16 \cdot 2$ & $6 \cdot 6$ & $17 \cdot 3$ & 6.7 & $<0.001$ \\
\hline Fibre $(g / d)$ & $25 \cdot 0$ & 8.7 & $25 \cdot 6$ & $8 \cdot 7$ & $25 \cdot 3$ & $7 \cdot 8$ & 0.066 \\
\hline Total cholesterol (mg/d) & 346 & 119 & 382 & 123 & 385 & 113 & $<0.001$ \\
\hline \multicolumn{8}{|l|}{ Food groups $(\mathrm{g} / \mathrm{d})$} \\
\hline Fruits & 370 & 204 & 372 & 205 & 352 & 199 & $<0.001$ \\
\hline Vegetables & 332 & 149 & 342 & 152 & 328 & 138 & 0.023 \\
\hline Cereals & 137 & 81 & 145 & 83 & 169 & 97 & $<0.001$ \\
\hline Meat & 125 & 55 & 136 & 55 & 146 & 58 & $<0.001$ \\
\hline Fish & 96 & 46 & 105 & 58 & 105 & 47 & $<0.001$ \\
\hline Legumes & 21 & 14 & 21 & 13 & 20 & 10 & 0.162 \\
\hline Dairy products & 403 & 227 & 374 & 218 & 309 & 197 & $<0.001$ \\
\hline Olive oil & 38 & 18 & 40 & 18 & 42 & 16 & $<0.001$ \\
\hline Nuts & 9 & 12 & 11 & 15 & 12 & 14 & $<0.001$ \\
\hline Soft drinks & 15 & 58 & 20 & 57 & 18 & 61 & 0.025 \\
\hline 13-point MedDiet questionnaire score $†$ & 8.34 & 1.86 & 8.35 & 1.90 & 8.26 & 1.84 & 0.56 \\
\hline
\end{tabular}

MedDiet, Mediterranean diet.

*One-way ANOVA tests.

†The 14-point questionnaire of adherence to the traditional MedDiet excluding the question regarding wine intake.

the correlation coefficients were significant, only weak linear associations were found among the variables. In general, the intake of RW was found to be positively correlated with the intake of beer, liquors and spirits, but not with that of other types of wines when analysing the entire sample or stratifying the sample by sex.

\section{Association between red wine consumption and the prevalence of the metabolic syndrome}

Among the 5801 participants included in the analyses, 3897 (67\%) fulfilled the criteria for the MetS. The metabolic risk parameters according to the RW intake categories are summarised in Table 4. Participants with the highest RW intake had lower BMI and heart rate, but higher BP. No significant differences were observed in total cholesterol or HDL-c concentrations across the groups. However, when these values were translated to MetS components taking into account the medications used to treat triacylglycerolaemia, hypertension or diabetes, fewer MetS cases were observed among the highest RW consumers, as well as a lower prevalence of abnormal waist circumference, high TAG concentrations or lipid-lowering treatment, low HDL-c concentrations, high BP or antihypertensive treatment, and high fasting plasma glucose concentrations or antidiabetic treatment.
The relative risk was calculated using logistic regression models with non-drinkers as the reference category. Risks calculated using crude models and after adjusting for possible confounders (sex, age, BMI, smoking status, educational level, physical activity, total energy intake and diet) differed significantly (Table 5). Consumption of less than one drink of RW per d was found to be associated with a significantly lower risk of the MetS in both the crude and adjusted models (OR 0.56, 95\% CI 0.45, 0.68; $P<0.001$ ). The same association was found when the fully adjusted OR for the highest RW intake category was estimated after excluding

Table 3. Pearson's correlation coefficients between the intake of different alcoholic beverage groups and that of red wine (drinks/d)

\begin{tabular}{|c|c|c|c|c|c|c|}
\hline & \multicolumn{2}{|c|}{$\begin{array}{l}\text { Entire sample } \\
\qquad(n 5801)\end{array}$} & \multicolumn{2}{|c|}{$\begin{array}{c}\text { Men } \\
(n 2433)\end{array}$} & \multicolumn{2}{|c|}{$\begin{array}{l}\text { Women } \\
\text { (n 3368) }\end{array}$} \\
\hline & $r$ & $P$ & $r$ & $P$ & $r$ & $P$ \\
\hline $\begin{array}{l}\text { White, } \\
\text { rosé and } \\
\text { sparkling } \\
\text { wines }\end{array}$ & 0.02 & 0.23 & -0.05 & 0.018 & 0.02 & 0.35 \\
\hline Beer & 0.17 & $<0.001$ & 0.09 & $<0.001$ & 0.10 & $<0.001$ \\
\hline Liquors & 0.12 & $<0.001$ & 0.08 & $<0.001$ & 0.10 & $<0.001$ \\
\hline Spirits & 0.14 & $<0.001$ & 0.08 & $<0.001$ & 0.09 & $<0.001$ \\
\hline
\end{tabular}


heavy drinkers ( $>2$ drinks/d for women and $>4$ drinks/d for men) in sensitivity analyses (data not shown). With regard to individual components of the MetS, participants who were in the highest RW intake category had a $41 \%$ lower risk of having an abnormal waist circumference (OR 0.59, 95\% CI $0 \cdot 46,0 \cdot 77 ; P<0 \cdot 001)$, a $58 \%$ lower risk of having low HDL-c concentrations (OR $0.42,95 \%$ CI $0.32,0.53 ; P<0.001$ ), a $72 \%$ lower risk of having high $\mathrm{BP}$ (OR 0.28, 95\% CI $0 \cdot 17$, $0.45 ; P<0.001)$ and a $33 \%$ lower risk of having high fasting plasma glucose concentrations (OR 0.67, 95\% CI 0.54, 0.82; $P<0.001)$ compared with non-consumers. A protective effect of RW intake on TAG concentrations that lost significance after adjustment for all potential confounders was also observed.

Analysis performed after stratifying the sample by sex revealed a lower risk of the MetS in women consuming $>1$ drink/d (OR 0.47, 95\% CI 0.30, 0.73; $P$ trend <0.001) than in men (OR 0.68, 95\% CI 0.53, 0.88; $P$ trend 0.004 ) after multivariate adjustment (Table 6). Analysis performed after stratifying the sample by age groups $(<70$ years and $\geq 70$ years) revealed that the effects of RW intake to be significant only for the youngest group (OR 0.49, 95\% CI 0.38, 0.63; $P$ trend $<0.001)$. When analysing the association between the prevalence of the MetS and RW intake among participants stratified by smoking status, a $43 \%$ reduction in the risk of the MetS in former or current smokers (OR 0.57, 95\% CI 0.43, 0.75; $P$ trend $<0.001)$ and a $40 \%$ reduction among those who never smoked were observed. For all stratum categories, a trend towards a lower risk of the MetS was observed in both the crude and adjusted models, although not all models achieved statistical significance.

The association between the prevalence of the MetS and the intake of different types of alcoholic beverages was also analysed. After adjusting for all confounders, beer intake was found to be associated with an increased risk of the MetS (OR 1.50, 95\% CI 1.08, 2.10; $P$ trend 0.005 ) due to its association with abdominal obesity (OR 1.49, 95\% CI 1.01, 2.19; $P$ trend 0.049). However, when the association between beer intake and waist:height ratio (anthropometric index of abdominal fat distribution) was analysed, the association was found to lose the statistical significance (OR 0.67; 95\% CI $0.23,1.97 ; P$ trend 0.970 ). None of the other metabolic criteria varied significantly with beer intake. Analysis of the intake of other alcoholic beverages in relation to the prevalence of the MetS revealed no significant associations for the intake of white, rosé and sparkling wines or for that of liquors and spirits, although the intake of these types of alcoholic beverages was scarce in the study population.

\section{Discussion}

In the present cross-sectional study of 5801 elderly participants at a high cardiovascular risk included in the PREDIMED study, 3897 MetS cases were found, representing a prevalence of $67.2 \%$, which was not unexpected given that only individuals with diabetes or three or more standard cardiovascular risk factors, including overweight or obesity, were eligible for inclusion in the study. In this setting, moderate RW

Table 4. Metabolic risk parameters of 5801 participants from the PREDIMED (Prevención con Dieta Mediterránea) cohort according to categories of red wine intake at baseline (energy-adjusted)

(Mean values and standard deviations; number of participants and percentages)

\begin{tabular}{|c|c|c|c|c|c|c|c|}
\hline & \multicolumn{2}{|c|}{ Non-drinkers (n 3037) } & \multicolumn{2}{|c|}{$0 \cdot 1-1$ drink/d (n 2086) } & \multicolumn{2}{|c|}{$>1$ drink/d (n 678) } & \multirow[b]{2}{*}{$P^{*}$} \\
\hline & Mean & SD & Mean & SD & Mean & SD & \\
\hline BMI $\left(\mathrm{kg} / \mathrm{m}^{2}\right)$ & $30 \cdot 7$ & $4 \cdot 1$ & $29 \cdot 7$ & $3 \cdot 6$ & $29 \cdot 2$ & $3 \cdot 3$ & $<0.001$ \\
\hline Waist:height ratio & 0.64 & 0.07 & 0.62 & 0.06 & 0.61 & 0.06 & $<0.001$ \\
\hline Systolic BP (mmHg) & $150 \cdot 4$ & $19 \cdot 5$ & $148 \cdot 6$ & $19 \cdot 2$ & $152 \cdot 7$ & $19 \cdot 6$ & $<0.001$ \\
\hline Diastolic BP (mmHg) & $82 \cdot 7$ & $10 \cdot 3$ & $83 \cdot 1$ & $10 \cdot 2$ & $84 \cdot 7$ & $10 \cdot 6$ & $<0.001$ \\
\hline Hearth rate (beats/min) & $72 \cdot 3$ & $11 \cdot 1$ & $69 \cdot 8$ & $10 \cdot 1$ & $69 \cdot 1$ & $10 \cdot 9$ & $<0.001$ \\
\hline Glucose (mg/dl) & $123 \cdot 1$ & $41 \cdot 3$ & $118 \cdot 7$ & $39 \cdot 0$ & $117 \cdot 1$ & $33 \cdot 7$ & $<0.001$ \\
\hline \multicolumn{8}{|l|}{ Lipid profile (mg/dl) } \\
\hline Total cholesterol & $206 \cdot 3$ & $37 \cdot 6$ & $205 \cdot 3$ & $37 \cdot 6$ & $206 \cdot 8$ & $37 \cdot 8$ & 0.579 \\
\hline HDL-c & $52 \cdot 8$ & $12 \cdot 1$ & $52 \cdot 1$ & $12 \cdot 4$ & $52 \cdot 8$ & $12 \cdot 0$ & 0.099 \\
\hline LDL-C & $128 \cdot 5$ & $33 \cdot 7$ & $130 \cdot 8$ & $36 \cdot 8$ & $131 \cdot 3$ & 33.5 & 0.032 \\
\hline TAG & $137 \cdot 3$ & 77.5 & $127 \cdot 8$ & $73 \cdot 6$ & $131 \cdot 8$ & $73 \cdot 7$ & $<0.001$ \\
\hline Metabolic syndrome and components & $n$ & $\begin{array}{l}\text { Percentage } \\
\text { of the total }\end{array}$ & $n$ & $\begin{array}{l}\text { Percentage } \\
\text { of the total }\end{array}$ & $n$ & $\begin{array}{l}\text { Percentage } \\
\text { of the total }\end{array}$ & $P \dagger$ \\
\hline Metabolic syndrome & 2268 & $74 \cdot 7$ & 1267 & $60 \cdot 7$ & 362 & $53 \cdot 4$ & $<0.001$ \\
\hline Abnormal waist circumference & 2560 & $84 \cdot 3$ & 1437 & $68 \cdot 9$ & 390 & $57 \cdot 5$ & $<0.001$ \\
\hline $\begin{array}{l}\text { High TAG concentrations or } \\
\text { lipid-lowering treatment }\end{array}$ & 1042 & $34 \cdot 3$ & 612 & $29 \cdot 3$ & 220 & $32 \cdot 4$ & $<0.001$ \\
\hline Low HDL-c concentrations & 999 & $32 \cdot 9$ & 585 & $28 \cdot 0$ & 99 & $14 \cdot 6$ & $<0.001$ \\
\hline High BP or antihypertensive treatment & 2990 & $98 \cdot 5$ & 1932 & $92 \cdot 6$ & 639 & $94 \cdot 2$ & $<0.001$ \\
\hline $\begin{array}{l}\text { High fasting plasma glucose } \\
\text { concentrations or antidiabetic treatment }\end{array}$ & 2125 & $70 \cdot 0$ & 1309 & $62 \cdot 7$ & 442 & $65 \cdot 2$ & $<0.001$ \\
\hline
\end{tabular}

BP, blood pressure; HDL-c, HDL-cholesterol; LDL-c, LDL-cholesterol.

* One-way ANOVA tests.

$\dagger \chi^{2}$ tests. 
Table 5. Risk of the metabolic syndrome and individual metabolic syndrome components according to red wine intake categories $(0 \cdot 1-1 \mathrm{drink} / \mathrm{d}$ and $>1 \mathrm{drink} / \mathrm{d}$ groups compared with the non-drinker group)

(Odds ratios* and $95 \%$ confidence intervals)

\begin{tabular}{|c|c|c|c|c|}
\hline & $0.1-1 \mathrm{drink} / \mathrm{d}$ & $P \dagger$ & $>1 \mathrm{drink} / \mathrm{d}$ & $P+$ \\
\hline \multicolumn{5}{|l|}{ Metabolic syndromeł } \\
\hline Unadjusted OR & 0.53 & \multirow[t]{2}{*}{$<0.001$} & 0.39 & \multirow{2}{*}{$<0.001$} \\
\hline $95 \% \mathrm{Cl}$ & $0.47,0.90$ & & $0.33,0.46$ & \\
\hline Multivariable OR§ & 0.64 & \multirow[t]{2}{*}{$<0.001$} & 0.56 & \multirow[t]{2}{*}{$<0.001$} \\
\hline $95 \% \mathrm{Cl}$ & $0.56,0.73$ & & $0.45,0.68$ & \\
\hline \multicolumn{5}{|c|}{ Abnormal waist circumference ( $>102 \mathrm{~cm}$ in men and $>88 \mathrm{~cm}$ in women or treatment) } \\
\hline Unadjusted OR & 0.40 & \multirow[t]{2}{*}{$<0.001$} & 0.24 & \multirow[t]{2}{*}{$<0.001$} \\
\hline $95 \% \mathrm{Cl}$ & $0.35,0.45$ & & $0.20,0.29$ & \\
\hline Multivariable OR§ & 0.64 & \multirow[t]{2}{*}{$<0.001$} & 0.59 & \multirow[t]{2}{*}{$<0.001$} \\
\hline $95 \% \mathrm{Cl}$ & $0.53,0.78$ & & $0.46,0.77$ & \\
\hline \multicolumn{5}{|c|}{ TAG ( $\geq 150 \mathrm{mg} / \mathrm{dl}$ or TAG-lowering medication) } \\
\hline Unadjusted OR & 0.76 & \multirow[t]{2}{*}{$<0.001$} & 0.89 & \multirow[t]{2}{*}{$0 \cdot 18$} \\
\hline $95 \% \mathrm{Cl}$ & $0.68,0.86$ & & $0.74,1.06$ & \\
\hline Multivariable OR§ & 0.76 & \multirow[t]{2}{*}{$<0.001$} & 0.87 & \multirow[t]{2}{*}{0.18} \\
\hline $95 \% \mathrm{Cl}$ & $0.66,0.86$ & & $0.71,1.06$ & \\
\hline \multicolumn{5}{|c|}{ HDL-cholesterol ( $<40 \mathrm{mg} / \mathrm{dl}$ in men and $<50 \mathrm{mg} / \mathrm{dl}$ in women or lipid-lowering treatment) } \\
\hline Unadjusted OR & 0.76 & \multirow[t]{2}{*}{$<0.001$} & 0.34 & \multirow[t]{2}{*}{$<0.001$} \\
\hline $95 \% \mathrm{Cl}$ & $0.68,0.87$ & & $0.27,0.42$ & \\
\hline Multivariable OR§ & 0.85 & \multirow[t]{2}{*}{0.015} & 0.42 & \multirow[t]{2}{*}{$<0.001$} \\
\hline $95 \% \mathrm{Cl}$ & $0.75,0.97$ & & $0.32,0.53$ & \\
\hline \multicolumn{5}{|c|}{ Blood pressure ( $\geq 130 / 85 \mathrm{mmHg}$ or antihypertensive treatment) } \\
\hline Unadjusted OR & 0.20 & \multirow[t]{2}{*}{$<0.001$} & $0 \cdot 26$ & \multirow[t]{2}{*}{$<0.001$} \\
\hline $95 \% \mathrm{Cl}$ & $0.14,0.28$ & & $0.17,0.40$ & \\
\hline Multivariable OR§ & 0.22 & \multirow[t]{2}{*}{$<0.001$} & 0.28 & \multirow[t]{2}{*}{$<0.001$} \\
\hline $95 \% \mathrm{Cl}$ & $0.16,0.31$ & & $0.17,0.45$ & \\
\hline \multicolumn{5}{|c|}{ Fasting plasma glucose ( $\geq 100 \mathrm{mg} / \mathrm{dl}$ or antidiabetic treatment) } \\
\hline Unadjusted OR & 0.70 & \multirow[t]{2}{*}{$<0.001$} & 0.79 & \multirow[t]{2}{*}{0.01} \\
\hline $95 \% \mathrm{Cl}$ & $0.62,0.79$ & & $0.66,0.95$ & \\
\hline Multivariable OR§ & 0.65 & \multirow[t]{2}{*}{$<0.001$} & 0.67 & \multirow[t]{2}{*}{$<0.001$} \\
\hline $95 \% \mathrm{Cl}$ & $0.57,0.74$ & & $0.54,0.82$ & \\
\hline
\end{tabular}

${ }^{*}$ OR were calculated using logistic regression analysis.

†Two-sided test of significance.

† The metabolic syndrome was considered to occur when at least three of the five metabolic criteria were fulfilled.

$\S$ Adjusted for sex, age, BMI, smoking status, educational level, physical activity, total energy intake and diet.

consumption was found to be associated with a decreased prevalence of the MetS, mainly by reducing the risk of having an abnormal waist circumference, high BP, low HDL-c concentrations and high fasting plasma glucose concentrations. This association was stronger in participants aged $<70$ years, in participants who were former or current smokers, and also in female participants. In fact, women consuming $>1 \mathrm{drink} / \mathrm{d}$ had a lower risk of the MetS than men. Several studies have demonstrated that women are more sensitive to the toxic effects of alcohol than men ${ }^{(23)}$. Therefore, the recommended upper limit of alcohol consumption for women is half of that recommended for men ${ }^{(24)}$. On the other hand, several studies have also reported the beneficial effects of moderate alcohol consumption in women even when consuming less amounts of alcohol when compared with men ${ }^{(25)}$. The results of the present study confirm the greater beneficial effects of moderate RW consumption on the incidence of the MetS in women than in men.

The intake of RW was weakly but positively associated with that of beer, liquors and spirits, but was not associated with the intake of other types of wines. This suggests that RW consumers are more likely to consume beer, liquors and spirits than white wine, rosé wine or sparkling wine. However, although significant, correlation coefficients were too low to draw conclusions. On the other hand, no association was found between the incidence of the MetS and the consumption of alcoholic beverages other than RW.

Wine is considered to be a key component of the traditional MedDiet. Several previous cohort and intervention studies have examined the effects of observed Mediterranean-type diets on the risk of the MetS and its components. The prospective Framingham Heart Study Offspring Cohort study was the first to report a protective effect of the MedDiet on the MetS, as participants in the highest quintile of MedDiet adherence had a $30 \cdot 1 \%$ incidence rate of the MetS compared with those in the lowest quintile category $(38.5 \% ; P=0 \cdot 01)^{(26)}$. Other, albeit not all ${ }^{(27)}$, cross-sectional studies carried out in Mediterranean countries ${ }^{(2,28-31)}$ have reported an inverse association between quartiles of adherence to the MedDiet and the incidence of the MetS. A recent meta-analysis of fifty studies has confirmed that the higher the adherence to the MedDiet, the lower the prevalence and progression of the $\mathrm{MetS}^{(32)}$. Interestingly, intervention studies including MetS patients have confirmed that the MedDiet may favour the regression of the MetS and prevent its progression ${ }^{(33,34)}$

However, few studies have analysed the role of moderate RW consumption in the prevalence of the MetS. Similar to the present study, a study carried out in the Canary Islands (Spain) showed the intake of wine, as well as that of other components of the traditional MedDiet such as fruits, 
Table 6. Stratified analyses of the risk of the metabolic syndrome according to red wine intake categories* (Odds ratios† and $95 \%$ confidence intervals)

\begin{tabular}{|c|c|c|c|c|c|}
\hline & Non-drinkers & $0.1-1$ drink/d & $>1$ drink/d & $P$ for trend & $P$ interaction \\
\hline \multicolumn{6}{|l|}{ Sex } \\
\hline \multicolumn{6}{|l|}{ Males } \\
\hline No. of cases/total & $482 / 738$ & $670 / 1113$ & $313 / 582$ & & \\
\hline Unadjusted OR & Ref & 0.80 & 0.61 & $<0.001$ & 0.41 \\
\hline $95 \% \mathrm{Cl}$ & & $0.66,0.97$ & $0.49,0.78$ & & \\
\hline Multivariable OR $\ddagger$ & Ref & 0.91 & 0.68 & 0.004 & 0.02 \\
\hline \multicolumn{6}{|l|}{ Females } \\
\hline $\begin{array}{l}\text { Females } \\
\text { No. of cases/total }\end{array}$ & $1786 / 2299$ & $597 / 973$ & $49 / 96$ & & \\
\hline Unadjusted OR & Ref & 0.46 & 0.30 & $<0.001$ & \\
\hline $95 \% \mathrm{Cl}$ & & $0.39,0.54$ & $0.20,0.45$ & & \\
\hline Multivariable OR $\ddagger$ & Ref & 0.52 & 0.47 & $<0.001$ & \\
\hline $95 \% \mathrm{Cl}$ & & $0.44,0.62$ & $0.30,0.73$ & & \\
\hline \multicolumn{6}{|l|}{ Age (years) } \\
\hline \multicolumn{6}{|l|}{$<70$} \\
\hline No. of cases/total & $1354 / 1801$ & $851 / 1414$ & $249 / 480$ & & \\
\hline Unadjusted OR & Ref & 0.50 & 0.36 & $<0.001$ & 0.18 \\
\hline $95 \% \mathrm{Cl}$ & & $0.43,0.58$ & $0.29,0.44$ & & \\
\hline Multivariable OR $\ddagger$ & Ref & 0.61 & 0.49 & $<0.001$ & 0.19 \\
\hline $95 \% \mathrm{Cl}$ & & $0.51,0.72$ & $0.38,0.63$ & & \\
\hline \multicolumn{6}{|l|}{$\geq 70$} \\
\hline No. of cases/total & $914 / 1236$ & $416 / 672$ & $113 / 198$ & & \\
\hline Unadjusted OR & Ref & 0.57 & 0.47 & $<0.001$ & \\
\hline $95 \% \mathrm{Cl}$ & & $0.47,0.70$ & $0.34,0.64$ & & \\
\hline Multivariable OR $\ddagger$ & Ref & 0.70 & 0.72 & 0.005 & \\
\hline $95 \% \mathrm{Cl}$ & & $0.56,0.88$ & $0.50,1.03$ & & \\
\hline \multicolumn{6}{|l|}{ Smoking status } \\
\hline \multicolumn{6}{|l|}{ Never } \\
\hline No. of cases/total & $1746 / 2297$ & $675 / 1117$ & 101/193 & & \\
\hline Unadjusted OR & Ref & 0.48 & 0.35 & $<0.001$ & 0.27 \\
\hline $95 \% \mathrm{Cl}$ & & $0.41,0.56$ & $0.26,0.47$ & & \\
\hline Multivariable OR $\ddagger$ & Ref & 0.60 & 0.60 & $<0.001$ & 0.004 \\
\hline $95 \% \mathrm{Cl}$ & & $0.51,0.71$ & $0.43,0.85$ & & \\
\hline \multicolumn{6}{|l|}{ Ever } \\
\hline No. of cases/total & $522 / 740$ & $592 / 969$ & $261 / 485$ & & \\
\hline Unadjusted OR & Ref & 0.66 & 0.48 & $<0.001$ & \\
\hline $95 \% \mathrm{Cl}$ & & $0.54,0.81$ & $0.38,0.61$ & & \\
\hline Multivariable OR $\ddagger$ & Ref & $0 \cdot 76$ & 0.57 & $<0.001$ & \\
\hline $95 \% \mathrm{Cl}$ & & $0.60,0.95$ & $0.43,0.75$ & & \\
\hline
\end{tabular}

Ref, reference.

* The metabolic syndrome was considered to occur when at least three of the five metabolic criteria were fulfilled. † OR were calculated using logistic regression analysis.

$\ddagger$ Adjusted for sex, age, BMI, smoking status, educational level, physical activity, total energy intake and diet.

vegetables and cereals, to be inversely associated with the prevalence of the MetS $S^{(23)}$. Indeed, it has been suggested that not all components of the MedDiet are likely to provide the same level of protection ${ }^{(35)}$.

Several studies with different designs have suggested that the greater health benefits of moderate consumption of RW might be related to its higher polyphenolic content compared with other alcoholic beverages. In fact, polyphenols may provide additional benefits to consumers of other alcoholic beverages by decreasing BP, inhibiting LDL oxidation, improving endothelial function and reducing inflammation and cell adhesion molecule levels ${ }^{(36)}$. In the present study, an association between regular RW consumption and hypertension was found, contrary to that reported in other studies $^{(37)}$. In a recent feeding trial, systolic and diastolic BP were found to be significantly decreased after 4 weeks of intervention with dealcoholised RW, but not after RW or gin interventions $^{(8)}$.
The best-established protective factor of alcohol intake is the increase in plasma HDL-c concentrations ${ }^{(38,39)}$. A metaanalysis of clinical studies assessing the effects of moderate alcohol consumption on HDL-c concentrations has indicated that the intake of $30 \mathrm{~g} / \mathrm{d}$ of ethanol increases HDL-c concentrations by a mean of $4.0 \mathrm{mg} / \mathrm{dl}$ and TAG concentrations by $5.7 \mathrm{mg} / \mathrm{dl}$, irrespective of the alcoholic beverage consumed. It has been estimated that an average intake of $30 \mathrm{~g}$ of ethanol/d would cause an estimated reduction of $24.7 \%$ in the risk of $\mathrm{CHD}^{(40)}$. In addition, both cross-sectional and intervention studies have shown that moderate RW consumption reduces the plasma concentrations of in vivo oxidised $\mathrm{LDL}^{(41,42)}$, which has been reported to be associated with the polyphenolic content of RW.

Moderate alcohol consumption has also been reported to be inversely associated with the risk of diabetes in a metaanalysis of observational studies that included data from 477200 men and women participating in prospective cohort 
studies. The dose-response trend showed that the alcohol intake of $22-24 \mathrm{~g} / \mathrm{d}$ had the strongest inverse association, but alcohol intake became deleterious over $60 \mathrm{~g} / \mathrm{d}$ in men and over $50 \mathrm{~g} / \mathrm{d}$ in women ${ }^{(43,44)}$.

In addition, randomised clinical trials have also demonstrated that moderate alcohol intake $(30 \mathrm{~g} / \mathrm{d})$ has beneficial effects on insulin and TAG concentrations and insulin sensitivity in non-diabetic postmenopausal women ${ }^{(45)}$, suggesting that moderate alcohol consumption decreases the risk of CVD and type 2 diabetes by improving insulin sensitivity.

Similar to that observed in other studies ${ }^{(46,47)}$, RW drinkers had significantly reduced BMI and waist circumference when compared with non-drinkers in the present study. Thus, moderate alcohol consumption, as observed in the Tromso Study ${ }^{(47)}$, as well as moderate RW consumption, as observed in the Danish Diet Cancer and Health Study ${ }^{(46)}$, exerts a beneficial effect by lowering the risk of abdominal obesity in women. Dietary factors including animal fat and refined carbohydrates are postulated to induce oxidative stress that stimulates inflammation in obesity. By contrast, some foods including wine, fruits, vegetables, nuts and others exert antioxidant and anti-inflammatory effects that may prevent the development of the $\operatorname{Met} S^{(48,49)}$.

The present study has a few limitations. First, as the study participants were elderly Spanish people at a high risk of CVD, findings from the study cannot be extrapolated to younger lower-risk populations from other countries. Furthermore, studying high-cardiovascular risk individuals is a limitation rather than an advantage for testing our hypothesis. Another limitation is the cross-sectional nature of the study, which does not allow inferring causal relationships between the MedDiet and the MetS. The present study also has strengths, such as the large sample size and the high number of participants with the MetS, the use of a validated FFQ and the ability to control for potential confounders due to recording of comprehensive data on risk factors, diet and sociodemographic variables. On the other hand, the study population is not representative of the general Spanish population. Although many potential confounders were controlled for in multivariate models, other unknown or unmeasured confounders may exist.

\section{Conclusions}

Compared with non-drinkers, moderate RW drinkers from an elderly population at a high cardiovascular risk have a lower risk of developing the MetS and having abnormal waist circumference, low HDL-c concentrations, high BP and hyperglycaemia, four of the five individual metabolic criteria included in its definition.

\section{Acknowledgements}

The authors thank all the volunteers involved in the PREDIMED study for their valuable cooperation.

The present study was supported in part by CICYT (AGL2010-22319-C03) from the Spanish Ministry of Science and Innovation (MICINN) and the Instituto de Salud Carlos III,
ISCIII (CIBERobn-CB06/03, PI1002658, and PI1001407). The CIBERobn is an initiative of the ISCIII, Spain. A. T.-R. received support from ISCIII (FI10/00265). A. M.-R. thanks the Juan de la Cierva' postdoctoral programme (JCI-2012-13463) from MEC (Ministerio de Economía y Competitividad). The MICINN, MEC and ISCIII had no role in the design and analysis of the study or in the writing of this article.

The authors' contributions are as follows: A. T.-R., A. M.-R., R. M. L.-R. and R. E. performed the statistical analyses, interpreted the data and wrote the first draft of the manuscript. All authors contributed to the writing and revision of the manuscript and approval of the final version to be published.

Conflicts of interest: R. M. L.-R. reports serving on the board of and receiving lecture fees from Research Foundation on Wine and Nutrition (FIVIN); receiving lecture fees from Cerveceros de España; and receiving lecture fees and travel support from PepsiCo. J. S.-S. reports serving on the board of and receiving grant support through his institution from the International Nut and Dried Fruit Council; receiving consulting fees from Danone; and receiving grant support through his institution from Eroski and Nestlé. F. A. reports receiving payment for the development of educational presentations from Menarini and AstraZeneca. E. R. reports serving on the board of and receiving travel support, as well as grant support through his institution, from the California Walnut Commission; serving on the board of the Flora Foundation (Unilever); serving on the board of and receiving lecture fees from Roche; serving on the board of and receiving grant support through his institution from Amgen; receiving consulting fees from Damm and Abbott Laboratories; receiving consulting fees and lecture fees, as well as grant support through his institution, from Merck; receiving lecture fees from Danone, Pace, AstraZeneca, and Rottapharm; receiving lecture fees and payment for the development of educational presentations, as well as grant support through his institution, from Ferrer; receiving payment for the development of educational presentations from Recordati; and receiving grant support through his institution from Sanofi-Aventis, Takeda, Daiichi Sankyo, Nutrexpa, Feiraco, Unilever, and Karo Bio. L. S.-M. reports serving on the boards of the Mediterranean Diet Foundation and the Beer and Health Foundation. X. P. reports serving on the board of and receiving payment for the development of educational presentations, as well as grant support through his institution, from Ferrer; receiving consulting fees from Abbott Laboratories; receiving lecture fees, as well as grant support through his institution, from Merck, Menarini, Unilever, and Roche; receiving lecture fees from Esteve, Lacer, and AstraZeneca; receiving payment for the development of educational presentations from Rubio; and receiving grant support through his institution from Sanofi-Aventis, Amgen, Pfizer, and Boehringer Ingelheim. R. E. reports serving on the board of and receiving lecture fees from the FIVIN; serving on the boards of the Beer and Health Foundation and the European Foundation for Alcohol Research (ERAB); receiving lecture fees from Cerveceros de España and Sanofi-Aventis; and receiving grant support through his institution from Novartis. No other potential conflicts of interest relevant to this article are reported. 


\section{References}

1. Eckel RH, Grundy SM \& Zimmet PZ (2005) The metabolic syndrome. Lancet 365, 1415-1428.

2. Babio N, Bulló M, Basora J, et al. (2009) Adherence to the Mediterranean diet and risk of metabolic syndrome and its components. Nutr Metab Cardiovasc Dis 19, 563-570.

3. Freiberg MS, Cabral HJ, Heeren TC, et al. (2004) Alcohol consumption and the prevalence of the metabolic syndrome in the US: a cross-sectional analysis of data from the Third National Health and Nutrition Examination Survey. Diabetes Care 27, 2954-2959.

4. Alkerwi A, Boutsen M, Vaillant M, et al. (2009) Alcohol consumption and the prevalence of metabolic syndrome: a metaanalysis of observational studies. Atherosclerosis 204, 624-635.

5. Barrio-Lopez MT, Bes-Rastrollo M, Sayon-Orea C, et al. (2013) Different types of alcoholic beverages and incidence of metabolic syndrome and its components in a Mediterranean cohort. Clin Nutr 32, 797-804

6. Chiva-Blanch G, Urpi-Sarda M, Ros E, et al. (2013) Effects of red wine polyphenols and alcohol on glucose metabolism and the lipid profile: a randomized clinical trial. Clin Nutr 32, 200-206

7. Botden IP, Draijer R, Westerhof BE, et al. (2012) Red wine polyphenols do not lower peripheral or central blood pressure in high normal blood pressure and hypertension. $\mathrm{Am} \mathrm{J}$ Hypertens 25, 718-723.

8. Chiva-Blanch G, Urpi-Sarda M, Ros E, et al. (2012) Dealcoholized red wine decreases systolic and diastolic blood pressure and increases plasma nitric oxide: short communication. Circ Res 111, 1065-1068.

9. Baba S, Osakabe N, Kato Y, et al. (2007) Continuous intake of polyphenolic compounds containing cocoa powder reduces LDL oxidative susceptibility and has beneficial effects on plasma HDL-cholesterol concentrations in humans. Am J Clin Nutr 85, 709-717.

10. Covas MI, Nyyssönen K, Poulsen HE, et al. (2006) The effect of polyphenols in olive oil on heart disease risk factors: a randomized trial. Ann Intern Med 145, 333-341.

11. Monagas M, Khan N, Andres-Lacueva C, et al. (2009) Effect of cocoa powder on the modulation of inflammatory biomarkers in patients at high risk of cardiovascular disease. Am J Clin Nutr 90, 1144-1150.

12. Pfeuffer M, Auinger A, Bley U, et al. (2013) Effect of quercetin on traits of the metabolic syndrome, endothelial function and inflammation in men with different APOE isoforms. Nutr Metab Cardiovasc Dis 23, 403-409.

13. Shin HC, Kim SH, Park Y, et al. (2012) Effects of 12-week oral supplementation of Ecklonia cava polyphenols on anthropometric and blood lipid parameters in overweight Korean individuals: a double-blind randomized clinical trial. Phytother Res 26, 363-368.

14. Miyazaki R, Kotani K, Ayabe M, et al. (2013) Minor effects of green tea catechin supplementation on cardiovascular risk markers in active older people: a randomized controlled trial. Geriatr Gerontol Int 13, 622-629.

15. Martínez-González MA, Corella D, Salas-Salvadó J, et al. (2012) Cohort profile: design and methods of the PREDIMED study. Int J Epidemiol 41, 377-385.

16. Willett WC, Howe GR \& Kushi LH (1997) Adjustment for total energy intake in epidemiologic studies. Am J Clin Nutr 65, 1220S-1228S, discussion 1229S-1231S.

17. Fernández-Ballart JD, Piñol JL, Zazpe I, et al. (2010) Relative validity of a semi-quantitative food-frequency questionnaire in an elderly Mediterranean population of Spain. Br J Nutr 103, 1808-1816.
18. Martínez-González MA, Fernández-Jarne E, Serrano-Martínez M, et al. (2004) Development of a short dietary intake questionnaire for the quantitative estimation of adherence to a cardioprotective Mediterranean diet. Eur J Clin Nutr 58, $1550-1552$.

19. Elosua R, Marrugat J, Molina L, et al. (1994) Validation of the Minnesota Leisure Time Physical Activity Questionnaire in Spanish men. The MARATHOM Investigators. Am J Epidemiol 139, 1197-1209.

20. O'Brien E, Waeber B, Parati G, et al. (2001) Blood pressure measuring devices: recommendations of the European Society of Hypertension. BMJ 322, 531-536.

21. Warnick GR, Knopp RH, Fitzpatrick V, et al. (1990) Estimating low-density lipoprotein cholesterol by the Friedewald equation is adequate for classifying patients on the basis of nationally recommended cutpoints. Clin Chem 36, 15-19.

22. Alberti KG, Eckel RH, Grundy SM, et al. (2009) Harmonizing the metabolic syndrome: a joint interim statement of the International Diabetes Federation Task Force on Epidemiology and Prevention; National Heart, Lung, and Blood Institute; American Heart Association; World Heart Federation; International Atherosclerosis Society; and International Association for the Study of Obesity. Circulation 120, $1640-1645$.

23. Fernandez-Sola J, Estruch R, Nicolas JM, et al. (1997) Comparison of alcoholic cardiomyopathy in women versus men. Am J Cardiol 80, 481-485.

24. Gunzerath L, Faden V, Zakhari S, et al. (2004) National Institute on Alcohol Abuse and Alcoholism report on moderate drinking. Alcohol Clin Exp Res 28, 829-847.

25. Di Castelnuovo A, Costanzo S, Bagnardi V, et al. (2006) Alcohol dosing and total mortality in men and women: an updated meta-analysis of 34 prospective studies. Arch Intern Med 166, 2437-2445.

26. Rumawas ME, Meigs JB, Dwyer JT, et al. (2009) Mediterranean-style dietary pattern, reduced risk of metabolic syndrome traits, and incidence in the Framingham Offspring Cohort. Am J Clin Nutr 90, 1608-1614.

27. Álvarez-León EE, Henríquez P \& Serra-Majem L (2006) Mediterranean diet and metabolic syndrome: a crosssectional study in the Canary Islands. Public Health Nutr $\mathbf{9}$, 1089-1098.

28. Kesse-Guyot E, Ahluwalia N, Lassale C, et al. (2013) Adherence to Mediterranean diet reduces the risk of metabolic syndrome: a 6-year prospective study. Nutr Metab Cardiovasc Dis 23, 677-683.

29. Paletas K, Athanasiadou E, Sarigianni M, et al. (2010) The protective role of the Mediterranean diet on the prevalence of metabolic syndrome in a population of Greek obese subjects. J Am Coll Nutr 29, 41-45.

30. Panagiotakos DB, Pitsavos C, Chrysohoou C, et al. (2004) Impact of lifestyle habits on the prevalence of the metabolic syndrome among Greek adults from the ATTICA study. Am Heart J 147, 106-112.

31. Tortosa A, Bes-Rastrollo M, Sanchez-Villegas A, et al. (2007) Mediterranean diet inversely associated with the incidence of metabolic syndrome: the SUN prospective cohort. Diabetes Care 30, 2957-2959.

32. Kastorini CM, Milionis HJ, Esposito K, et al. (2011) The effect of Mediterranean diet on metabolic syndrome and its components: a meta-analysis of 50 studies and 534,906 individuals. J Am Coll Cardiol 57, 1299-1313.

33. Esposito K, Marfella R, Ciotola M, et al. (2004) Effect of a Mediterranean-style diet on endothelial dysfunction and markers of vascular inflammation in the metabolic syndrome: a randomized trial. JAMA 292, 1440-1446. 
34. Salas-Salvado J, Fernandez-Ballart J, Ros E, et al. (2008) Effect of a Mediterranean diet supplemented with nuts on metabolic syndrome status: one-year results of the PREDIMED randomized trial. Arch Intern Med 168, 2449-2458.

35. Martínez-González MA \& Sánchez-Villegas A (2004) The emerging role of Mediterranean diets in cardiovascular epidemiology: monounsaturated fats, olive oil, red wine or the whole pattern? Eur J Epidemiol 19, 9-13.

36. Arranz S, Chiva-Blanch G, Valderas-Martínez P, et al. (2012) Wine, beer, alcohol and polyphenols on cardiovascular disease and cancer. Nutrients 4, 759-781.

37. Zilkens RR, Burke V, Hodgson JM, et al. (2005) Red wine and beer elevate blood pressure in normotensive men. Hypertension 45, 874-879.

38. Ellison RC, Zhang Y, Qureshi MM, et al. (2004) Lifestyle determinants of high-density lipoprotein cholesterol: the National Heart, Lung, and Blood Institute Family Heart Study. Am Heart J 147, 529-535.

39. Klatsky AL (2010) Alcohol and cardiovascular health. Physiol Behav 100, 76-81.

40. Rimm EB, Williams P, Fosher K, et al. (1999) Moderate alcohol intake and lower risk of coronary heart disease: meta-analysis of effects on lipids and haemostatic factors BMJ 319, 1523-1528.

41. Schroder H, Marrugat J, Fito M, et al. (2006) Alcohol consumption is directly associated with circulating oxidized low-density lipoprotein. Free Radic Biol Med 40, 1474-1481.
42. Estruch R, Sacanella E, Mota F, et al. (2011) Moderate consumption of red wine, but not gin, decreases erythrocyte superoxide dismutase activity: a randomised cross-over trial. Nutr Metab Cardiovasc Dis 21, 46-53.

43. Baliunas DO, Taylor BJ, Irving H, et al. (2009) Alcohol as a risk factor for type 2 diabetes: a systematic review and meta-analysis. Diabetes Care 32, 2123-2132.

44. Koppes LL, Dekker JM, Hendriks HF, et al. (2005) Moderate alcohol consumption lowers the risk of type 2 diabetes: a meta-analysis of prospective observational studies. Diabetes Care 28, 719-725.

45. Davies MJ, Baer DJ, Judd JT, et al. (2002) Effects of moderate alcohol intake on fasting insulin and glucose concentrations and insulin sensitivity in postmenopausal women: a randomized controlled trial. JAMA 287, $2559-2562$.

46. Fumeron F, Lamri A, Emery N, et al. (2011) Dairy products and the metabolic syndrome in a prospective study, DESIR. J Am Coll Nutr 30, 454S-463S

47. Wilsgaard T \& Jacobsen BK (2007) Lifestyle factors and incident metabolic syndrome. The Troms $\varnothing$ Study 1979-2001. Diabetes Res Clin Pract 78, 217-224.

48. Kimokoti RW \& Brown LS (2011) Dietary management of the metabolic syndrome. Clin Pharmacol Ther 90, 184-187.

49. Dandona P, Aljada A, Chaudhuri A, et al. (2005) Metabolic syndrome: a comprehensive perspective based on interactions between obesity, diabetes, and inflammation. Circulation 111, 1448-1454. 